\title{
La imagen sociológica. Crítica y autorreflexividad en la Sociología de Georg Simmel
}

\author{
Lucía Wegelin ${ }^{1}$
}

Fecha de recepción: 18 de julio de 2013

Fecha de aprobación: 27 de septiembre de 2013

\begin{abstract}
Resumen:
Este escrito se sumerge al interior de la obra de Georg Simmel con el propósito de recuperar la impronta crítica de su Sociología a través de la diferenciación entre dos modos en los que la imagen aparece en sus reflexiones. Se construirá aquí esa diferencia entre la imagen urbana y la imagen sociológica como crítica de la anterior, realizando un recorrido por el movimiento autorreflexivo de su pensamiento. Su sociología será interrogada en relación con sus diagnósticos sobre la modernidad para determinar el modo en el que sus conceptos sociológicos cargan con su crítica hacia la modernidad urbana. Por lo tanto, los objetivos deeste trabajoson:a-Distinguirellugar dela imagen en los diagnósticos de Simmel sobre la cultura moderna; b-Determinar las rasgos imaginales de los conceptos sociológicos simmelianos; c-Interrogar el modo en el que las imágenes sociológicas intervienen críticamente sobre la cultura moderna.
\end{abstract}

Palabras clave: Simmel, imagen sociológica, imagen urbana.

\begin{abstract}
:
This paper explores the work of Georg Simmel in order to recover the critical stamp of his sociology through his two modes of image. This study develops the difference between the urban image and the sociological image as a criticism of the former, following the self-reflexive movement of Simmel's thought. Simmel's diagnosis of modernity is questioned in order to determine the way in which his sociological concepts imply a criticism of urban modernity. The objectives of this study are: a) to define the place of image within Simmel's diagnosis of modern culture, b) to determine the imaginal characteristics of Simmel's sociological concepts, and c) to question the way sociological images critically intervene in modern culture.
\end{abstract}

Key words: Simmel, sociological image, urban image.

1 Licenciada en Sociología por la Universidad de Buenos Aires, Maestranda en Sociología por la Universidad de San Martín, Doctoranda en Ciencias Sociales por la Universidad de Buenos Aires. Becaria CONICET tipo II con sede en el Instituto de Investigaciones Gino Germani. Rivadavia 5126, piso 17 dto. 10, Ciudad Autónoma de Buenos Aires, C.P. 1425.

luciawegelin@gmail.com 
La obra de un pensador no sistemático como Georg Simmel se ofrece como dispersión de múltiples temas, perspectivas y preocupaciones. Sus escritos no se ordenan en una unidad total que les dé sentido sino que coinciden en la heterogeneidad: a veces como sociólogo, a veces como crítico de arte, a veces como filósofo, aborda temas como el amor, el número 3, Goethe o la vida en las grandes urbes. Simmel invita a reconocer la singularidad de su perspectiva nunca enunciada sistemáticamente sino sólo desplegada en el movimiento que atraviesa la heterogeneidad de sus escritos. Sin embargo, es posible ensayar más de una lectura que intente unificar esa variedad de alguna manera y por lo tanto componer distintas imágenes unitarias de la perspectiva original simmeliana.

El procedimiento de lectura que se desplegará aquí tendrá como faro a la categoría de "imagen". Ella permitirá abrir un camino a través de la heterogeneidad de los escritos de Simmel dado que cruza al menos dos espacios centrales de su obra. En primer lugar, aparece cuando se ensaya una descripción de los modos de percepción modernos en las grandes urbes. Al mismo tiempo, la Sociología simmeliana se construye en torno a imágenes que son usadas entonces como herramientas epistemológicas. La imagen define tanto el carácter de sus construcciones epistemológicas como el modo de la experiencia sensible predominante en las grandes urbes que, como Berlín, explotaban en los albores del siglo XX. Por eso, el recorrido por los modos en los que la imagen aparece en los escritos simmelianos permitirá poner en escena el movimiento autorreflexivo que caracteriza a su perspectiva.

\section{La imagen en la cultura del fin de siecle}

La forma trágica de la cultura moderna.

La pregunta por los modos en los que se construye la Sociología de Georg Simmel no puede despegarse de los diagnósticos 
que el pensador formula en el cambio entre los siglos XIX y XX. Su Sociología es autorreflexiva porque se construye en interacción recíproca con el objeto de estudio, la sociedad de la época; vale decir, es una sociología eminentemente moderna. Ella no puede comprenderse al margen de sus diagnósticos sobre la modernidad no sólo por el carácter socialmente determinado de todo conocimiento sino porque en este caso la construcción de su sociología asume reflexivamente la relación con su objeto. La sociología simmeliana es síntoma y diagnóstico de la experiencia moderna de principios del siglo XX. Tal como lo lee Salvi (2011), toma como objeto aquello de lo que es un producto.

La construcción de la Sociología como un modo particular de mirada sobre lo social supone, en este caso, la pregunta por las determinaciones del objeto sobre la mirada que se pretende construir. No necesariamente esa percepción de las condiciones de posibilidad para el conocimiento de lo social se realiza en un momento previo al de la mirada estrictamente cognoscitiva. El movimiento de autorreflexividad supone una concepción procesual del conocimiento, en permanente reconstrucción a partir de su interacción con el objeto.

Por lo tanto, aquello que puede reconocerse como diagnóstico de época, que determina las condiciones de posibilidad e imposibilidad para el conocimiento de la misma no es un diagnóstico aséptico, que existe previamente y al margen de las especificidades de la mirada sociológica simmeliana. Sin embargo, sí es posible diferenciar los textos en los que esa mirada se construye, clasificables como epistemológicos, y otros textos en donde se intentan delinear tendencias generales de la sociedad de la época como la Filosofía del dinero y algunos ensayos como "El concepto y la tragedia de la cultura" (Simmel, 1988), "El conflicto de la cultura moderna" (Simmel, 1923) y "Las grandes urbes y la vida del espíritu" (Simmel, 1986).

Sería posible reconocer en esos textos algunas características de la mirada sociológica pero en ellos también se rompe con cier- 
tos límites formales en el afán de reconocer y delinear tendencias generales de época. Para comprender con qué rompen y qué rasgos de la Sociología de Simmel se hacen presentes en estos textos sobre las tendencias de la época sería necesario comenzar por reponer sus reflexiones epistemológicas. Sin embargo, dado que intento exponer el carácter autorreflexivo de esas reflexiones, comenzaré por el otro extremo. Esto significa no empezar por la imagen como construcción epistemológica, sino por la imagen tal como aparece, según la propia mirada simmeliana, en la sociedad contemporánea a Simmel, vale decir, la época en la que la economía monetaria se ha expandido decididamente y las grandes urbes transformaban el estilo de vida de los individuos.

Es posible reconocer una preocupación que cruza la dispersión de heterogeneidades de los textos de Simmel y compone a ese sujeto-sociólogo que está por detrás de la variedad: la relación entre individuo y sociedad y al mismo tiempo los modos en los que esa relación afecta al individuo. La intención de reconocer procesos históricos en el objeto sociológico, es decir, en la sociedad, no obnubila la preocupación por el modo en el que esos procesos transforman la vida de los individuos, y esto porque el concepto de sociedad no está hipostasiado en la teoría simmeliana como totalidad supraindividual.

El diagnóstico central de Simmel sobre su época es aquel que se configura bajo la forma de la "Tragedia de la cultura moderna" y allí mismo no se piensa un proceso que se ubica en el plano de la totalidad social (la mirada simmeliana nunca se posa sobre ese plano) sino un modo de la relación entre el individuo y la sociedad.

La tragedia indica la forma que asume la cultura en la época moderna. La cultura es definida como un proceso que habita en el dualismo fundamental entre sujeto y objeto. Supone la salida del sujeto hacia su expresión objetiva y el consecuente desarrollo de ese sujeto que se cultiva a sí mismo recogiendo contenidos que están fuera de sí pero con los que se encuentra como en una armonía predeterminada (Simmel, 1988: p. 207). En este proceso se 
desarrollan entonces las posibilidades inmanentes al sujeto al mismo tiempo que aumenta la producción objetiva. La dualidad está inscripta en la propia naturaleza del sujeto en tanto para realizarse él requiere una salida de sí, su consumación como espíritu subjetivo supone su objetivación, es decir, la producción de algo objetivo que existirá más allá del sujeto.

La cultura es, por lo tanto, una totalidad que encierra una grieta en su interior que puede expresarse como la diferencia entre la cultura subjetiva y la cultura objetiva, diferencia que nace de la propia necesidad del sujeto de objetivarse en pos de lograr su realización. Ahora bien, la diferencia cualitativa entre sujeto y objeto convierte a la grieta en la que vive el proceso cultural en una paradoja: el sujeto es una vida que fluye continuamente, es decir, existe en tanto está creando, produciendo, hasta que llega a su fin absoluto en el instante de la muerte, es entonces móvil incesantemente y finito; por su parte, el objeto es una forma de la fijeza, inamovible pero válido al margen del tiempo, producto fijo pero infinito en tanto que existe más allá de la vida del sujeto que se objetivó en ellos.

La paradójica grieta se muestra como tragedia con el acrecentamiento de la separación entre los dos elementos que hacían funcionar a la cultura como totalidad. El destino ineludible que estaba inscripto en el propio ser dual de la cultura determinó que la cultura objetiva sobreviva a los sujetos y por lo tanto se acreciente a un ritmo inalcanzable por la cultura subjetiva. La división del trabajo permitió la concreción del destino trágico de la cultura como totalidad al incentivar el crecimiento acelerado del mundo objetivo y al mismo tiempo su autonomía; dado que muchos sujetos intervienen en la producción de cada objeto, el valor objetivo se vuelve más independiente. Resulta de ese proceso una inadecuación cuantitativa (por la inmensidad del mundo de objetos producidos), y cualitativa (por la autonomía que adquiere al ser producido por varios sujetos y no por uno solo y al mismo tiempo por no ser producido para un sujeto particular 
sino para el mercado) entre sujeto y objeto, que impide la concreción del proceso cultural como totalidad. Los objetos producidos por el sujeto ya no permiten el crecimiento del espíritu subjetivo porque se autonomizan, se alejan de su origen subjetivo y de su fin subjetivo y así quiebran el proceso cultural.

La relación entre sujeto y objeto en el proceso cultural se manifiesta también en el campo del conocimiento y por lo tanto este sufre la misma tragedia epocal y está determinado por la misma grieta fundamental que la tragedia moderna pone al descubierto. Dado que el conocimiento científico es uno de los modos en el que los sujetos desarrollan la cultura objetiva se sufre en esta esfera la misma separación entre los desarrollos científicos y las posibilidades de que la cultura subjetiva crezca al mismo ritmo asimilando todos estos desarrollos. Este fenómeno se realiza como especialización del conocimiento; sus desarrollos se vuelven aprehensibles sólo para especialistas y la relación con la totalidad se invisibiliza. Pero al mismo tiempo, esta autonomización del desarrollo objetivo del conocimiento en relación al sujeto deviene en una autonomización de los métodos en relación a los contenidos. La esfera del conocimiento adquiere una lógica propia que se auto-reproduce y de esta manera, los principios formales se vuelven fijos e independientes de los contenidos específicos.

Al interior de este diagnóstico sobre la cultura y los modos modernos del conocimiento surge la propuesta simmeliana: como crítica a la autonomización de las formas y como sociología formal al mismo tiempo. La doble locación de la imagen en sus escritos debe encuadrarse en esta paradoja más amplia que supone que frente a la primacía de formas estáticas en la modernidad deben encontrarse aquellas formas dinámicas que no nieguen al movimiento. 


\section{Primacía de la vista en la ciudad moderna: la imagen urbana}

Las imágenes en la ciudad moderna niegan al movimiento en su interior en tanto que ellas se suceden indefinidamente y a un ritmo acelerado como producciones objetivas que se vuelven impermeables para el sujeto, o incluso lo vuelven impermeable a él. La sucesión de imágenes al mismo tiempo compone el movimiento acelerado propio de la experiencia moderna pero al hacerlo reproduce la dinámica de la tragedia de la cultura como proceso más general. La tragedia de la cultura se realiza como experiencia subjetiva en el urbanita dado que la hipertrofia de la cultura objetiva se traduce en la experiencia subjetiva del urbanita como indolencia.

La cultura llega a su destino trágico dado que la objetivación como modo de realización del hombre deviene en alienación subjetiva, es decir en extrañamiento del objeto que debía ser su realización. Pero Simmel no sólo describe esta situación como tendencia dominante en el plano de la sociedad sino que observa, al mismo tiempo, los efectos que este modo trágico de la cultura moderna tiene sobre los sujetos. Al menos un aspecto de lo que el joven Marx llamaba alienación es reconocido por Simmel: la alienación con el objeto, y no sólo con el objeto que él produce sino con el que sus pares producen. Aunque no logren el desarrollo del espíritu subjetivo, los sujetos están en continuo contacto con esos objetos culturales que les producen entonces los "sufrimientos culturales" que Simmel analiza en "Las grandes urbes y la vida del espíritu".

En ese renombrado ensayo, el acrecentamiento de la vida nerviosa es explicado en los términos de una nueva relación con las imágenes. El "rápido e ininterrumpido intercambio de impresiones internas y externas" (Simmel, 1986: p. 247) supone una estimulación visual constante a un ritmo acelerado. La gran urbe produce una transformación en los fundamentos sensoriales de la vida anímica. 
En una de las digresiones de su Sociología. Estudios sobre las formas de socialización, Simmel realiza un esbozo de una sociología de los sentidos. Allí sostiene que el tráfico de la gran ciudad se basa mucho más en el ver que en el oír. Los medios de transporte públicos ponen a los hombres enfrentados teniéndose que verse mutuamente sin hablar.

La cuidad moderna hace que las relaciones sensibles entre los hombres queden confiadas al sentido de la vista. Esto contribuye a la desorientación y sensación de aislamiento en la ciudad porque la vista es el sentido que nos acerca a lo más duradero, según las apreciaciones simmelianas, permite percibir lo que permanece, es decir, "el ser" de lo que se nos presenta. La vista permite conocer las huellas del pasado pero también el cambio en el estado de ánimo que se expresa en el rostro.

Y sin embargo, en la gran ciudad se suceden rápida e infinitamente muchas imágenes que no permanecen y no permiten constituir una imagen del otro. La imagen que prolifera en la ciudad moderna no es una petrificación del devenir sino que es ella misma la que marca el ritmo del fluir de las percepciones. Ese ritmo que las imágenes imponen afecta al individuo, a su relación con los otros individuos y a su relación con las cosas. La primacía de la vista se asocia a esta estimulación de imágenes, definiendo así una soberanía de la imagen en la vida urbana moderna.

Esta soberanía de uno de los sentidos es consecuencia de las nuevas formas de socialización modernas y al mismo tiempo es causa de nuevas transformaciones. Tal como sostiene Sabido Ramos en su artículo El sentir de los sentidos y las emociones en la Sociología de Georg Simmel, "el cuerpo es producto del sentido y produce sentido, Las emociones y los sentidos corporales son productos sociales y producen sociedad". (Ramos, 2007: p. 215)

Simmel sostenía que la vista tiende a percibir lo igual entre los hombres mientras que el oído lo diferente. Tanto para la percepción de los otros hombres como la de las mercancías, la pri- 
macía de la vista determina que estas percepciones sean más abstractas, más alejadas de lo particular. La vista permite unidades más abstractas que reúnen lo común a todos. La falta de carácter que él reconoce en la relación de los individuos con las cosas y de los individuos entre sí puede asociarse a esta primacía de la vista que se traduce en una primacía del entendimiento, la facultad capaz de abstraer. El urbanita se crea un órgano de defensa frente a esa violencia amedrentadora de las imágenes urbanas, reaccionando a esas corrientes de cultura objetiva externas con el entendimiento y no con el ánimo (Gemut). El ritmo de las imágenes cambiantes requieren del entendimiento que pueda abstraerse de las diferentes impresiones y concebir lo igual, lo que permanece, poniendo un freno a los estímulos y protegiendo la sensibilidad del individuo que se resguarda tras el entendimiento calculador.

La economía monetaria y la consiguiente división del trabajo, que explican la tragedia de la cultura moderna, transforman la vida de los individuos en las grandes urbes en dos planos: tanto la relación entre las facultades como la relación entre los sentidos se redefinen; el entendimiento y la vista adquieren primacía simultáneamente.

Las transformaciones sociales producen entonces sufrimientos en los individuos, quienes se protegen de la neurastenia, esa sobre-estimulación a la que están sometidos. Este acrecentamiento de la vida nerviosa produce una redefinición de los modos de percepción y reacción que termina realizándose como indolencia, Blasiertheit. La objetivación del sujeto como cultura objetiva se convierte en lo que Lukacs reconocería como un modo de la cosificación cuando se produce esta indiferenciación de lo particular de las cosas. Ellas se vuelven como nulas para el sujeto indolente, se tiñen de una coloración opaca. Este modo de percepción subjetivo es, para Simmel, el reflejo de la economía monetaria triunfante en tanto el dinero equilibra uniformemente las diversidades, funciona como nivelador. Se percibe la falta de carácter de todo como reacción a la exposición a demasiada diversidad: "en 
virtud del crecimiento cuantitativo de la excitación nerviosa del individuo esta cae en su extremo contrario, el peculiar fenómeno adaptativo de la indolencia."

Esta actitud no sólo se produce frente a las cosas, mercancías equivalenciadas por la economía monetaria, sino que también supone una actitud frente a los otros individuos, desconocidos y, por eso, indiferenciados. La autoconservación del individuo frente a los estímulos de la gran ciudad le exige un comportamiento negativo en sus relaciones sociales, un comportamiento de reserva. La reserva frente a los efímeros contactos trae consigo una silenciosa aversión, una extranjería y repulsión mutua. La antipatía provoca las distancias sin las que la vida en la gran ciudad sería imposible e incluso, según Simmel, promiscua. La reserva y la antipatía son nuevas formas de socialización dominantes en la vida urbana, modos en los que se configura el tejido social en la ciudad.

En la Filosofía del dinero, Simmel estudia las transformaciones del estilo de vida que el dinero produce como símbolo de la economía monetaria que estructura la sociedad de la época en el espacio de las grandes urbes. Aquella indiferencia frente a la variedad de estímulos producidos por imágenes cambiantes se traduce en el estilo de vida como falta de carácter debido a la extensión del dinero y el entendimiento que proceden a través de la abstracción de las particularidades y, por lo tanto, se convierten en igualadores en las relaciones en donde median. El dinero, por ser el equivalente universal, y el entendimiento por concentrarse sólo en los medios más adecuados y valorar equitativamente los fines. La falta de carácter se vuelve la regla en las relaciones de los hombres entre sí y de los hombres con las cosas. La obliteración de lo particular en la vida los hombres supone al mismo tiempo una mayor objetividad. Las relaciones entre los hombres y de ellos con las cosas se vuelven calculables y así se protege al sujeto de la sobreabundancia de estímulos divergentes. 


\section{Fundamentos de una epistemología moderna}

La reflexión sobre los sufrimientos del individuo en su relación con la sociedad y las tendencias que cruzan esa relación se ordenan bajo la configuración del concepto de estilo de vida. El estilo es un modo de relacionar lo particular con una ley general que tiene su origen como concepto en el campo artístico. Indica la relación de la obra de arte, una individualidad cerrada sobre sí misma, con una ley general compartida con otras obras individuales. Es una particularidad de la obra lo que se vuelve general cuando se reconoce un estilo. El estilo de vida no es entonces una forma que regula las vidas particulares obliterando la individualidad. Es, en cambio, una particularidad que se repite como una regularidad entre individualidades. Se construye a partir de la vida de los individuos pero los supera como una síntesis espiritual superior, configurada, en este caso, por el sociólogo. Sin embargo, según escribe Simmel en "El ámbito de la Sociología" (Simmel, 2002), el "estilo" tiene el mismo status de realidad que la "sociedad" o, en su terminología específica, "las formas de socialización". Son abstracciones de lo particular que configuran una nueva realidad con tanta existencia como aquello que parecen ser sus unidades mínimas (las obras de arte singulares o los individuos que entran en interacciones sociales).

En el primer capítulo de los dos libros más importantes sobre Sociología de Simmel ("El problema de la Sociología" en Sociología. Estudio sobre las formas de socialización y "El ámbito de la Sociología" en Cuestiones fundamentales de Sociología) aparece como problema el status de realidad de los conceptos en relación a la fundación de la Sociología como ciencia. Dado que el objeto de la Sociología es, según Simmel, el resultado de una abstracción, es decir, un concepto, se vuelve necesario pensar el status de realidad de esa abstracción que funda a la ciencia como tal. Este análisis le permite a Simmel reconocer el carácter abstracto de todos los posibles objetos científicos: no es más real un individuo por ser la unidad mínima de la sociedad ya que, de hecho, nunca 
percibimos al individuo como totalidad sino que realizamos una abstracción a partir de una serie de impresiones segmentadas que recibimos en relación a él. De la misma manera, una molécula o un átomo, imposibles de percibir con los sentidos, requieren de una abstracción, se producen en el interior del conocimiento subjetivo de la realidad.

Esta postura sobre la primacía de la abstracción en todos los ámbitos del conocimiento abre el camino para el perspectivismo simmeliano. La diferencia entre las ciencias sociales está dada por el objeto que recortan de la realidad, la distancia diferenciada con la que producen la abstracción. Pero esas abstracciones son tan reales como las configuraciones del "Tú" que el "Yo" realiza en la vida cotidiana: es imposible captarlo como totalidad y por lo tanto realiza operaciones (de abstracción) para completar la imagen del otro a partir de lo que sí percibe de él. Por eso pueden haber múltiples imágenes del "Tú" dependiendo de qué operaciones se realicen.

La especificidad de las Ciencias Sociales es que son sus propios objetos (los sujetos) quienes realizan abstracciones para configurar totalidades. Acercándose a la postura de Dilthey, para Simmel hay una diferencia entre el objeto del conocimiento natural y el del conocimiento social: los a prioris no están en el sujeto que se opone al objeto como observador sino que son los sujetos internos al objeto "Sociedad" quienes poseen en su estructura mental los a prioris de lo social (Simmel, 1939).

En las discusiones del neokantismo de la época reaparecía la dicotomía de las dos primeras Críticas escritas por Kant, entre la Razón pura teórica y la Razón pura práctica, disfrazada bajo la separación entre las Ciencias de la naturaleza y las Ciencias del espíritu. Sin insertarse explícitamente en las discusiones que marcaban a la academia alemana del cambio de siglo, Simmel se orienta hacia una postura hermenéutica que piensa la posibilidad del conocimiento social a partir de los modos en los que los individuos que configuran a lo social son capaces de concebirlo 
en la vida cotidiana. Eso le valió tanto la acusación de Weber de psicologicismo, como el reconocimiento que hace de su obra la tradición hermenéutica.

En este mismo sentido se relata el nacimiento de la Sociología en el comienzo de "El problema de la Sociología". La esfera del conocimiento (de los hechos) y la de la vida cotidiana (de los valores) poseen en la "actualidad" moderna de Simmel una relativa autonomía. Sin embargo, las dos esferas se conectan y es a partir de esta conexión que se puede explicar el nacimiento de una ciencia de lo social: la aparición de la masa en la vida urbana expone la gran determinación de lo social sobre la vida de los individuos y es este hecho social de la esfera de la vida cotidiana de los individuos lo que produce una transformación en la esfera del conocimiento, generando el reclamo de una ciencia que estudie esas determinaciones que se han vuelto evidentes.

La Sociología de Simmel se construye sobre esa necesidad de reconectar las dos esferas que la crítica kantiana había pretendido separar. No sólo lo hace a través de la elección de los objetos (propios de la vida social cotidiana, como el asa, el secreto, la coquetería o la prostituta) sino a través de la confección de una epistemología que parte de los modos en los que los sujetos se conciben a sí mismos en la vida cotidiana.

Este peculiar modo embrionario de hermenéutica explica el doble lugar de la imagen en los escritos simmelianos. Dado que la imagen tenía esa prioridad en la vida urbana de los individuos resulta determinante también en el modo de conocer esas sociedades. La imagen aparece entonces como modo de percepción cotidiano y como elemento en el que se produce el conocimiento de lo social.

Al reflexionar sobre los modos de percepción Simmel sostiene que es la realidad misma la que se da a conocer en imágenes; esta realidad, en un principio, viene dada como un complejo de imágenes, como una superficie de fenómenos yuxtapuestos en forma continua (Simmel, 2002: p. 30). En la vida urbana la realidad se transfor- 
ma continuamente, las imágenes adquieren una gran velocidad y por lo tanto los individuos están expuestos a un volumen de imágenes cambiantes cada vez mayor. La imagen es el modo de captación más inmediato de la realidad y al mismo tiempo es, para Simmel, la realidad misma. Percibimos imágenes de la realidad que son ellas mismas reales. Esto significa que el perspectivismo simmeliano no supone un relativismo extremo que diluye la realidad por ser ella siempre relativa sino que se funda en un realismo conceptual que nunca deja de sostener la realidad de las imágenes percibidas desde las distintas perspectivas.

\section{Rastros de Goethe}

En esos tiempos modernos en los que la relación entre el individuo y la sociedad se muestra como problemática, el dualismo se ha desarrollado como marca constitutiva de los modos de concebir el mundo bajo los nombres del idealismo y el materialismo. La tragedia de la cultura es la explicación simmeliana del modo en el que el dualismo se ha desplegado hasta el extremo en los grandes centros poblacionales regidos por la economía monetaria. La escisión vive, según Simmel, en la separación progresiva del sujeto y el objeto en el mundo de la cultura, en la oposición entre la pretensión de autonomía del individuo y la totalidad social, en la oposición entre sujeto y objeto de conocimiento y en el antagonismo entre "el mecanismo natural y el sentido y valor de las cosas". Es el propio neokantismo de la época el que se esconde detrás de esta lectura simmeliana de la realidad. En el texto "Kant y Goethe. Dos concepciones modernas del mundo" se presentan esas lecturas dualistas enlazadas, como parte del ser dual del ser moderno y Kant no aparece como un ejemplo de esa separación sino como un intento de unión contrapuesto al intento de Goethe.

La lectura que Simmel realiza de la obra de Kant termina conduciéndolo hacia Goethe, recorrido que se realiza decididamente en su ensayo "Kant y Goethe". La tradición de los dos pensado- 
res es continuada por Simmel dado que, al igual que las filosofías de ellos, su sociología se construye como superación de las dos concepciones del mundo (Weltanschaungen) que, según él, habían determinado la época moderna: idealismo y materialismo.

La unificación kantiana se apoya sobre el sujeto en tanto presenta al mundo fenoménico como su representación. Como base del contraste entre sujeto y objeto se coloca el hecho de la conciencia y del conocer en general, y el mundo (...) se determina por el hecho positivo de que lo sabemos (Simmel, 1949: p. 226). La conciencia como condición para la existencia del fenómeno, es decir, la "conceptualidad de lo real" es un punto de partida para la Sociología simmeliana que reconoce la mediación subjetiva como necesaria para la configuración del objeto de su ciencia. La crítica de Simmel a esa forma kantiana de resolver el dualismo es que funda a lo real en el sujeto de conocimiento. La epistemología simmeliana no se apoya sobre un sujeto de conocimiento sino sobre el sujeto real, que no sólo conoce la realidad sino que la valora, le da sentido, en otras palabras, la vive.

Esta lectura de Kant como un intento de unificación fracasa porque su sistema se funda en una separación, la de las facultades de la conciencia subjetiva. Es el sujeto (trascendental) la instancia última de unificación de las tres críticas dedicadas a tres actividades de ese sujeto: conocer, obrar libremente y juzgar. Tal como sostiene Simmel, Kant construye una filosofía de los límites mientras que Goethe una verdadera filosofía de la unidad.

Por eso, es posible leer en los escritos epistemológicos simmelianos un realismo conceptual que hunde sus raíces en Goethe, más que una conceptualidad de lo real al modo kantiano. Tanto los conceptos (por ejemplo el de sociedad) como las imágenes percibidas son realidad a pesar de suponer algún grado de abstracción. Cada modo de abstracción supone una distancia distinta con los fenómenos pero no se diferencia por su "grado de existencia". En su libro sobre Goethe (Simmel, 2005), Simmel recupera del escritor alemán su crítica a la opinión científica co- 
rriente. En esta "opinión científica corriente" se sostiene la separación radical del objeto de conocimiento y el sujeto que conoce en la relación cognitiva. Se supone, al mismo tiempo, la unicidad de la verdad que descansa sobre el objeto, independiente entonces del sujeto que la busca. Se la reconoce como idéntica al contenido objetivo y se descarta al proceso cognitivo subjetivo como parte de esa verdad. El concepto de verdad goethiano se opone a esa separación y reducción del proceso de conocer porque se funda en una concepción del ser como unitario y, por lo tanto, se sostiene una homogeneidad de esencia entre la naturaleza y los hombres, entre el sujeto y el objeto.

Goethe insiste con la máxima pasión en la objetividad del conocer, en la observación abnegadamente fiel, en la exclusión de toda mera subjetividad y, al propio tiempo, sin conciencia de la menor contradicción, sólo quiere reconocer como verdadero lo que lo ayuda a conocer y se adapta a la existente condición de su espíritu (Simmel, 2005: p. 46) lo fecundo para la vida del individuo. El conocimiento es entonces un "acaecimiento cósmico" en el que se consuma la unidad de la humanidad con la naturaleza, unidad que sólo puede darse si esa humanidad se atomiza y la vida de cada individuo es fecundada por la objetividad.

Ese acaecimiento cósmico es una excepción en los tiempos signados por la tragedia de la cultura moderna. El conocimiento del mundo cultural (aunque Goethe se refería fundamentalmente al conocimiento de la naturaleza) sería aquella actividad que logra eso que resulta cada vez más difícil en la modernidad: que el objeto producido por sujetos vuelva a ellos de alguna manera, los cultive. Conocer supondría superar la separación entre el sujeto que conoce y el objeto conocido, producir un encuentro entre esos dos términos que en la modernidad tienden a separase cada vez más.

Esta verdad definida en términos de Goethe como lo fecundo para el individuo se reformula en el análisis de Simmel sobre la cultura como el cultivo de la vida del individuo. La metáfora del 
cultivo y de la fecundidad se sostienen sobre la continuidad, que ambas concepciones reconocen, entre la naturaleza y la cultura. Para Simmel la cultura es el desarrollo de aquello que está en la naturaleza del hombre como semilla; se puede reconocer la separación entre los dos términos así como se puede reconocer la diferencia entre el día y la noche, a pesar de que no sean más que momentos continuos sin ningún punto de quiebre absoluto.

La continuidad es la que habilita el propio concepto de individuo que aparece en los textos que Simmel reconoce como parte de su sociología filosófica. Un individuo que está en conflicto con la pretensión de la totalidad social de que él funcione como parte pero que al mismo tiempo se funde con ella. La autoperfección del individuo como ideal objetivo desarrollada en el capítulo IV de Cuestiones fundamentales de sociología, permite una superación de la oposición altruismo-egoísmo que determinaba el problema sociológico de la relación entre individuo y sociedad. La pretensión del individuo de desarrollarse como totalidad autónoma no es necesariamente una tendencia egoísta, así como el desarrollo de la particularidad del individuo como parte del todo no es siempre una tendencia altruista. Se supone una armonía predeterminada entre los individuos y el mundo social que provoca que el desarrollo de la personalidad individual en toda su perfección pueda redundar en un incremento de valor del todo social. La división del trabajo que reclama al individuo como parte no siempre lo cercena como totalidad sino que su lugar singular en el todo puede coincidir con el desarrollo de su personalidad individual.

Esta idea de la verdad como lo fecundo para la vida del individuo da lugar a una multiplicidad de verdades que se reconcilian en tanto se asientan sobre una misma totalidad siempre en movimiento. En Goethe esa unidad tiene un carácter panteísta, que se resuelve en una unidad orgánico-natural última. Es ese el fundamento del realismo de los conceptos que sostiene Goethe, mientras que en el caso de Simmel será la vida el fundamento de 
la unidad que se realiza en la cultura como proceso móvil unitario. Esa es la condición de posibilidad para un relativismo como el de Simmel que sigue sosteniendo un único concepto de verdad.

Así como la unidad entre sujeto y objeto supone la antinomia entre los términos, la verdad como unidad se realiza en la multiplicidad de perspectivas. La lucha es para Simmel una forma de la unidad, no una ruptura del lazo social sino una forma de socialización específica. En este sentido es que se puede seguir sosteniendo la posibilidad de la unidad de la verdad a pesar de que se la defina como la representación fecunda para el individuo. Por lo tanto, este relativismo (que es un modo de perspectivismo) no es una simple reducción a un subjetivismo que corrige el objetivismo de "la opinión científica corriente". La verdad no está en los fenómenos y tampoco es el resultado de una actividad subjetiva.

Por ejemplo, el concepto de sociedad como "forma de socialización" es verdadero en tanto no se reduce a una creación del sujeto-sociólogo cognoscente, pero tampoco existe como ya dado en los fenómenos. Es un concepto que hay que construir pero la posibilidad para su construcción está dada por el hecho de que opera en la realidad fenoménica. Allí se encuentran contenidos subjetivos diferentes que se expresan bajo la misma forma, como las diferentes motivaciones individuales que asumen la forma de socialización del matrimonio; y al mismo tiempo, motivaciones individuales similares que asumen diferentes formas, como la motivación económica puede realizarse como competencia o como asociación. Las diferentes formas para un mismo contenido y los distintos contenidos para la misma forma fundamentan la posibilidad del sujeto cognoscente de separar la forma de contenido y quedarse con las formas de socialización como objeto para la Sociología. El concepto "forma de socialización" es, por lo tanto, una abstracción real. 
Los conceptos tienen entonces un carácter realista. Vale decir, la verdad no se resuelve ni en el sujeto ni en el objeto considerados aisladamente (la verdad no resulta de la intención subjetiva pero tampoco existe sin la mediación que el sujeto realiza), sino que es la ocasión real de su unidad. Unidad panteísta en Goethe o vitalista en Simmel que no sólo se opone a la dualidad sujetoobjeto sino que también se propone superar el dualismo platónico entre idea y fenómeno.

En la exposición de Simmel el Urphänomen ${ }^{2}$ aparece como elemento central de la teoría de la verdad de Goethe y es presentado como un fenómeno, pero distinto a los ordinarios en tanto es el caso más puro (Simmel, 2005: p. 64). Con este concepto se pretende superar la separación entre las cosas y la verdad, división sostenida por explicaciones que, o bien explican los fenómenos remitiéndose a otros fenómenos y se quedan por lo tanto siempre en ese plano, o bien consideran al fenómeno como el resto dejado por la totalidad superior configurada por la idea. La síntesis goethiana concibe a la figura como revelación directa de la idea (Simmel, 2005: p. 60). Esa figura es visible, es decir, percibida con los sentidos, pero sólo cierta intuición (la propia del artista por ejemplo) puede funcionar como intuición intelectual y percibir en la figura el "anuncio y la visibilidad de la idea". Cuando es así el fenómeno no es un simple fenómeno sino un Urphänomen, y no porque sea anterior al resto y pueda entenderse como su génesis, sino porque allí se ve de modo más puro lo que está en todos los otros como posibilidad, la idea.

En tanto el Urphänomen quiebra la separación entre un plano fenoménico y otro ideal, al igual que se afirmaba acerca de la verdad en la que este concepto se sostiene, sólo podrá ser percibido de tal manera por un "hombre entero" que no utilice sus facultades separadamente. La intuición intelectual que logra percibir el

2 Podría ser traducido como fenómeno originario, o arquetípico. 
Urphänomen como tal supone la superación de la antítesis entre sensibilidad y razón. Al mismo tiempo no es sólo una capacidad receptiva, sino también creativa que por lo tanto puede encontrarse privilegiadamente en los artistas. El propio Goethe poseía, según Simmel, un modo de ver que es ya un configurar.

Se destaca la vista como el sentido privilegiado para esa intuición que tiene esa capacidad doble, pasiva y activa al mismo tiempo. De esa manera, característica en los artistas, deben conjugarse las facultades del hombre entero para conocer en la teoría del conocimiento sociológico simmeliana. En Sociología. Estudio sobre las formas de socialización. Simmel reconoce el procedimiento intuitivo que guía su investigación pero lo explica a partir del estado poco desarrollado de la ciencia sociológica. Sin embargo, "hay muchos aspectos de los acontecimientos en los que la subordinación bajo ese concepto (el de forma de socialización) o bajo el concepto de contenido sigue siendo arbitraria" por lo que no es posible establecer un método preciso que funcione indefectiblemente en todos los casos. Por eso la intuición será siempre necesaria al enfrentarse a problemas particulares siempre nuevos. Ya en el "Prólogo" a Philosophische Kultur (editado en castellano como Cultura femenina y otros ensayos y también como Sobre la aventura) se reconoce la imposibilidad de fijar un método enunciable independientemente de los análisis particulares debido al lugar central de la intuición en la epistemología simmeliana.

Simmel no utiliza en sus propias reflexiones epistemológicas la idea del Urphänomen pero sí aparece el realismo conceptual que sostiene a esa idea. El conocimiento de lo social se funda sobre la intención de superar la división kantiana entre la razón teórica y la razón práctica, la división platónica entre idea y fenómeno, y la división propia de "la opinión científica corriente" entre sujeto y objeto de conocimiento. El conocimiento es entonces ese acaecimiento cósmico que permite la unidad.

El antisistematismo del sociólogo alemán no supone la independencia de los fragmentos que componen su obra sino que se 
fundan en la más profunda unidad. Mientras que para Goethe es el organismo lo que se convierte en el símbolo del mundo, para Simmel la vida es la forma de la unidad que supone el movimiento y la transformación y por lo tanto da lugar a la multiplicidad de fragmentos. La expresión de esta comunión en las perspectivas se resume en la frase con la que Simmel define el modo de la unidad en los textos de Goethe: "sólo siendo un devenir puede lo uno ser diverso".

\section{Carácter imaginal del concepto: la imagen crítica}

Hasta aquí han aparecido el concepto de sociedad y la imagen que configuran los individuos en su vida cotidiana como dos modos de la abstracción real. La diferencia entre ambos está determinada por la distancia con la que contemplan y configuran la realidad, haciendo uso, ambos, de esa doble capacidad, pasiva y activa, propia del sentido de la visión. Por lo tanto, la mayor distancia del concepto, su alejamiento con respecto a las percepciones cotidianas, no elimina su propio carácter imaginal. El neologismo resulta de la traducción de la palabra alemana bildlich, una adjetivación derivada del sustantivo Bild que significa imagen.

Aquello que resulta de la capacidad doble de la visión es siempre una imagen. Esa doble potencialidad es la que Simmel le reconoce en su "Esbozo sobre sociología de los sentidos". La mirada es expresiva y receptiva al mismo tiempo y por eso habilita la reciprocidad más plena entre individuos. Tal como sostiene Ramón Reséndiz García, “Tomar y dar es la significación sociológica del sentido de la vista” (Reséndiz, 2011: p. 157).

En este carácter imaginal del concepto simmeliano se pone en juego también la productividad o creatividad que participa en todo proceso de abstracción. Según el segundo a priori de lo social presentado por Simmel, la imagen del "Tú" es completada por un acto creativo del "Yo" que une los rasgos que conoce del otro gracias a operaciones como la generalización, la potencia- 
ción o la fundición del ser individual con su círculo. Es entonces una condición de posibilidad de lo social que los individuos asuman ese rol creativo en la producción de las imágenes de los otros, precisamente para que no se vean abrumados por rasgos de desconocidos que no llegan a ser configurados como imágenes por la fugacidad de la vida urbana. El concepto sociológico exige, entonces, esa misma participación creativa pero, en este caso, del investigador. La Sociología simmeliana interviene críticamente sobre los modos de percepción urbanos de los comienzos del siglo XX rehabilitando esa creatividad en la configuración de las imágenes sobre esa sociedad.

Por todo esto, el perspectivismo simmeliano debe comprenderse también en su sentido óptico. Su pensamiento sociológico, que se construye sobre ese perspectivismo, no abandona nunca a los conceptos pero tampoco a su carácter imaginal. El realismo conceptual pone en juego la doble capacidad de la visión, que recibe una imagen que al mismo tiempo configura. Por eso, en el decir de Simmel, la Sociología es una disposición de la mirada particular, aquella que trabaja como un microscopio.

En otro sentido, el carácter imaginal del concepto simmeliano se manifiesta en la movilidad de su objeto de estudio que en la gran ciudad se caracteriza por la sucesión de imágenes a gran velocidad. Cuando Simmel se propone construir a la Sociología como ciencia se puede reconocer ese pensamiento que vive siempre en movimiento, nunca permanece fijo. No sólo en las formas de lo social que analiza se agita siempre un movimiento interior sino que el modo de construir al objeto mismo de su sociología asume la posibilidad de un objeto móvil, los pequeños hilos que permiten ver a la sociedad en status nascens, constituyéndose continuamente. Entonces, el objeto de la sociología no está compuesto sólo por las relaciones ya institucionalizadas (la familia, el Estado, la religión) sino por todas las pequeñas relaciones que construyen a la sociedad como una unidad viva, en constante movimiento (por eso la mirada sociológica tiene la par- 
ticularidad de ser microscópica). De esta manera, la sociología de Simmel intenta disolver la fijeza de aquellas relaciones ya cosificadas, asumiendo entonces ese carácter dinámico de las imágenes en la ciudad moderna en su propia construcción conceptual. Su sociología no reproduce las formas sociales ya cristalizadas ni contribuye a la cosificación porque no piensa con conceptos que fijen al movimiento. Las formas de socialización son ellas mismas dinámicas y por lo tanto dan lugar en la teoría al dinamismo de la vida social moderna.

El movimiento autorreflexivo que había sido señalado previamente se expone aquí en función del dinamismo de las imágenes en la ciudad moderna que reclama el mismo dinamismo en los conceptos que pretenden pensarla. No es que su sociología sea simplemente un reflejo especular de la sociedad de su época sino que se construye más bien un juego de espejos del que resultan conceptos sociológicos modernos para pensar la modernidad.

Ahora bien, el movimiento y su ritmo en las grandes urbes habían sido analizados por Simmel como dinamismo entre las imágenes. Vale decir, el ritmo acelerado de las grandes urbes era concebido como sobreabundancia de impresiones que se manifestaban como sucesión acelerada de imágenes cambiantes. Sin embargo, el dinamismo del que se hace cargo el concepto de "formas de socialización" no sólo se refleja en la inestabilidad de esas formas sino que el movimiento también aparece en el interior de cada una de ellas. A diferencia de las imágenes que se suceden en las grandes urbes, las formas de socialización son separadas del ritmo de su fluir y por lo tanto hay lugar en el interior de ellas mismas para el movimiento.

Siguiendo con la metáfora óptica, es posible definir a la sociología simmeliana como un procedimiento de zoom, vale decir, un acercamiento de la mirada sobre aquello que en la vida cotidiana de la ciudad se percibe como una imagen veloz y cambiante. La perspectiva sociológica permite detenerse sobre aquello que está siempre fluyendo para focalizar la mirada sobre esa imagen 
y reconocer los movimientos que se suceden al interior de ella. La imagen sociológica retoma algo de la imagen como fenómeno de la vida urbana pero al mismo tiempo transforma algo de ella. Pretende reproducir el dinamismo de su velocidad al concentrarse en aquello que pasa, pero, al mismo tiempo, interviene sobre ese fluir al detenerse sobre cada forma constituyente de la sociedad. Es esa intervención la que abre la posibilidad de que el conocimiento de lo social se convierta en crítica de la sociedad que tiene por objeto.

El sociólogo supera la amenaza producida por el sobreestímulo de imágenes en la experiencia urbana y puede detenerse en cada una de ellas, descubriendo que poseen, siempre, una tensión en el interior, tensión que pasa desapercibida para el urbanita. En la configuración de sus imágenes sociológicas, él recupera el rol productivo que estaba adormecido en los modos de percepción del urbanita. El carácter imaginal del concepto sociológico no es simplemente mímesis de la realidad (que se presenta en imágenes en la ciudad moderna) sino que es una intervención sobre la realidad, porque tiene una dinámica interna que la imagen cosificada que percibe el urbanita no tiene.

Se están presentando entonces dos modos de la imagen en los textos de Georg Simmel. Se llama a uno "imagen urbana", cosificada, cerrada sobre sí misma, que sólo pasa y afecta con su ritmo a los sujetos con los que se encuentra. Se llama a la otra modalidad de la imagen, "imagen crítica", porque interviene críticamente sobre ese otro primer modo.

Las formas de socialización son el objeto de la sociología y, por surgir de una disposición de la mirada, una abstracción que se realiza desde un punto de vista, son presentadas en este escrito como un modo de imagen. Al mismo tiempo, al ser definidas por Simmel como los hilos que están constituyendo en cada momento a la sociedad, tienen ese carácter pasajero de las imágenes urbanas. Las acciones recíprocas en las sociedades modernas configuran unidades de corto plazo, son, sobre todo, configuraciones 
efímeras y por lo tanto son esas formas de socialización, las más mínimas y transitorias, las que a Simmel, como sociólogo de la modernidad, le interesan principalmente (antes que otras formas de socialización más estáticas en el tiempo como las grandes instituciones). El concepto de forma de socialización se caracteriza por volver visible a esas interacciones mutuas fugaces entre los hombres.

El primer momento sociológico, fundacional, es el de la abstracción de la forma, pero eso no significa que los escritos sociológicos de Simmel se reduzcan a un listado de formas de socialización. Vale decir, su Sociología formal está lejos de ser una reducción de la realidad a formas fijas. El trabajo sociológico consiste en abstraer la forma y observar sus variaciones históricas, de contenido, subjetivas; vale decir, congelar esas interacciones fugaces en una forma que permita observarla en su interior.

Ese es el modo en el que efectivamente procede en su Sociología... con la forma de la lucha, la subordinación o el secreto y en Cuestiones fundamentales de Sociología con la "sociabilidad" (Gesselichkeit) como forma pura de la socialización. Las analiza como formas y se concentra en sus variaciones de grado, históricas o según los contenidos. Por otro lado, también se pregunta por cómo influye la cantidad de individuos, el espacio, el cruce o la autoconservación de los círculos sociales en las acciones recíprocas en general. Por último, también analiza la relación entre las interacciones recíprocas y los individuos en el capítulo sobre "La ampliación de los grupos y la formación de la individualidad" y a través de las figuras sociales que se producen en función de determinadas formas de socialización, como el extranjero o el pobre. En el mismo sentido se desarrollan los capítulos de Sociología histórica, sobre la relación entre la masa y el individuo, y de Sociología filosófica, sobre los conceptos de individuo y sociedad en los siglos XVIII y XIX, en Cuestiones fundamentales de Sociología.

En estos análisis pertenecientes a los dos libros centrales de Sociología de Simmel conviven contradicciones y ambigüedades 
en el interior de cada una de las formas de socialización y de las figuras sociales analizadas. Esas tensiones, que han sido pensadas como dualidad, antagonismo o ambivalencia (Salvi, 2011), son las que permiten hablar del movimiento al interior de las imágenes sociales simmelianas.

La lucha es un ejemplo paradigmático de la dualidad porque es en sí misma una forma de la unidad que se sostiene en la divergencia y por lo tanto se le atribuye una fuerza disolvente y disociadora. Este capítulo sobre la lucha pone en evidencia que, para Simmel, (...) es unidad la sintesis general de las personas, energías y formas que constituyen un grupo, la totalidad final en que están comprendidas, tanto las relaciones de unidad en sentido estricto, como las de dualidad (Simmel, 1939: p. 250).

En esta definición de Simmel que aparece en ese análisis sobre la unidad de la lucha como forma antagónica, se vuelve evidente el fundamento de la tensión que habita en todas las formas que él analiza: como interacciones recíprocas las formas de socialización son siempre unidades que encierran una dualidad mínima entre dos términos. De esa manera la sociedad está siempre en relación con el individuo en cada acción recíproca. Las formas de socialización se sostienen en esa tensión entre el individuo y la sociedad, que atraviesa, como preocupación, la obra de Simmel. Ese es el secreto que habita en las formas de socialización como categorías sociológicas, están siempre tensionadas desde el interior y el análisis sociológico simmeliano se concentra, haciendo foco, en los modos en los que esa tensión se desarrolla.

Incluso la figura de la soledad es analizada por Simmel como realización de formas de socialización y es por lo tanto dual. De la misma manera que Robinson Crusoe no está solo porque lleva en él a la sociedad británica (imperialista) del siglo XVIII, el hombre solitario no se desprendió de todas las acciones recíprocas sino que a pesar de ellas y en relación a ellas es que se siente solo.

En los análisis de Simmel se lee siempre una dualidad que tensiona a la forma unitaria que constituye su objeto. Por ejem- 
plo, el secreto se analiza como tensión entre el saber algo y la posibilidad siempre latente de contarlo, que, si se realiza, destruye al secreto mismo. Esta forma sólo vive mientras se sostenga la tensión interior que provoca que se vuelva evidente aquello mismo que se esconde. De manera análoga, la tensión aparece en la figura del extranjero como aquel que está adentro de la comunidad pero también afuera, porque es el que viene de lejos y se queda cerca. A través de su presencia lo próximo es lejano y lo lejano es acercado. La experiencia del individuo en las grandes urbes ha sido presentada también en una tensión, en ese caso entre la mayor nivelación y la mayor diferenciación. Es la misma tensión que vive en el interior de la moda como aquello que produce diferenciación con objetos exclusivos y que por eso es perseguido por todos, produciendo a largo plazo una nivelación. Allí es cuando la moda cambia y propone un nuevo modo de diferenciación. La forma de la fidelidad se analiza en la figura del converso como forma dual, dado que para ser fiel a la nueva comunidad ha tenido que ser infiel a la comunidad de la que formaba parte anteriormente. Y por último, uno de los objetos privilegiados por Simmel (por la posición que ocupa en el mundo moderno): el dinero, que es presentado en La filosofía del dinero como lo más fluido, en tanto es capaz de expresar a la variedad de todas las cosas, pero, al mismo tiempo, como lo más estable, en tanto es el equivalente general.

\section{Reconfiguraciones finales}

Más allá de las diferencias entre los modos en los que los dos términos de la tensión se relacionan en cada uno de estos ejemplos, el recorrido a través de los análisis simmelianos permite reconocer algo que se repite. La tensión que reaparece en todas las formas de socialización y figuras sociales determina la singularidad de la visión sociológica de Simmel.

Esos dualismos, ambigüedades y antagonismos, que podrían ser leídos como inconsistencias o zonas poco claras del pensa- 
miento simmeliano, se delatan en estos ejemplos, y en otros tantos, como un modo singular del pensamiento. La definición de una vez y para siempre de lo uno como idéntico a sí no es el modo en el que se desenvuelven las formas en el pensamiento de Simmel, pensamiento que Frederic Jameson ha caracterizado como horizontal u oscilatorio (...) como el ejercicio de un tipo de pensamiento dialéctico (Jameson, 1999: p. 276).

En su ensayo "La hesitación teórica: el predecesor sociológico de Benjamin", Jameson expone cómo esa aparente inconsistencia aparece tanto en las reflexiones sobre la posibilidad de la libertad en "Las grandes urbes y la vida del espíritu" como en la Filosofía del dinero. Caracteriza a esas ambigüedades como un modo de proceder del pensamiento simmeliano a través de la duda que se conserva como tal en la indefinición, el concepto como siempre incompleto, "un tipo de pensamiento orientado por lo procesual". Allí se conservan las antinomias sin resolver así como la tensión entre individuo y sociedad no se resuelve nunca.

Esta tensión interior a los conceptos conforma también ese carácter imaginal del pensamiento de Simmel, a pesar de que no se corresponde con ninguna característica del modo de percepción de las imágenes en la vida en las grandes urbes. Por eso es que aquí irrumpe la crítica sobre esas imágenes cosificadas, cerradas sobre sí mismas, que se suceden como golpes interceptando al individuo de la ciudad moderna. La intervención crítica de la sociología simmeliana reside en esta diferencia entre el sentido de la vista en las grandes urbes y la mirada sociológica.

Esta sociología que se construye como crítica a la autonomía de las formas y sociología formal al mismo tiempo es posible porque trabaja precisamente con estas imágenes críticas de la sociedad de su época y sus modos de percepción. La imagen sociológica simmeliana es moderna pero al mismo tiempo es crítica de la modernidad y por eso mismo puede decirse que se construye a través de un movimiento autorreflexivo que se ha intentado exponer en este escrito. 


\section{Bibliografía}

Reséndiz García, Ramón (2011): “La sociología configurativa de Georg Simmel: imaginación teórica y armonía metodológica”, en Georg Simmel y la modernidad. Bogotá, Centro Editorial, Falcultad de Ciencias Humanas. p. 157.

Sabido Ramos, Olga (2007): “El sentir de los sentidos y las emociones en la sociología", en Georg Simmel. Una revisión contemporánea. España, Anthropos en coedición con la Universidad Autónoma Metropolitana.

Salvi, Valentina (2011): “Sociología de las relaciones recíprocas: dualismo, antagonismo y ambivalencia", en Georg Simmel y la modernidad. Bogotá, Universidad Nacional de Colombia.

Simmel, Georg (1988): "El concepto y la tragedia de la cultura", en Sobre la aventura. Barcelona, ediciones Península. (Gustau Muñoz).

Simmel, Georg (1923): "El conflicto de la cultura moderna". Córdoba, Sección de librería y publicaciones de la Facultad de Derecho y Ciencias Sociales de la Universidad Nacional de Córdoba. (Carlos Astrada).

Simmel, Georg (1986): “Las grandes urbes y la vida del espíritu”, en El individuo y la libertad. Barcelona, ediciones Península. (Salvador Mas).

Simmel, Georg (2002): Cuestiones fundamentales de Sociología. Barcelona, Gedisa editorial. (Ángela Ackerman Pilári).

Simmel, Georg (1939): Sociología. Estudio sobre las formas de socialización. Buenos Aires, Editora Espasa-Calpe.

Simmel, Georg (1949): “Kant y Goethe. Para la historia de la concepción moderna del mundo", en Goethe. Buenos Aires, Nova. (José Rovira Armengol).

Simmel, Georg (2005): Goethe. Buenos Aires, Prometeo. 